Please quote as: Wegener, R. \& Leimeister, J. M. (2012): Peer Creation of ELearning Materials to Enhance Learning Success and Satisfaction in an Information Systems Course. In: Proceedings of the 20th European Conference on Information Systems (ECIS 2012), Barcelona, Spain. 


\title{
PEER CREATION OF E-LEARNING MATERIALS TO ENHANCE LEARNING SUCCESS AND SATISFACTION IN AN INFORMATION SYSTEMS COURSE
}

\author{
Wegener, René, Kassel University, Pfannkuchstraße 1, 34121 Kassel, Germany, \\ wegener@uni-kassel.de \\ Leimeister, Jan Marco, Kassel University, Pfannkuchstraße 1, 34121 Kassel, Germany, \\ leimeister@uni-kassel.de
}

\begin{abstract}
Creating up-to-date high quality learning materials requires significant resources many instructors cannot afford, especially when it comes to appealing eLearning materials. Peer creation may help to address this challenge. However, existing concepts of peer learning focus mostly on enhancing active discussion and reflection. Thus far, little to no research has addressed processes of systematically creating modular, re-usable learning materials and evaluated the extent to which these materials can enrich the learning experience. To close this gap, we transferred principles of traditional peer learning onto the creation of self-contained, high quality eLearning materials: Web Based Trainings that served as an interactive script and multiple-choice tests as peer assessments. These learning materials were used in a large-scale Information Systems course ${ }^{l}$. We analyzed user logs, measured learning outcomes by a pre-and post-power-test $(n=164)$ and evaluated learner satisfaction by an online questionnaire $(n=128)$. Results show a significant correlation between usage of the peer created eLearning materials and learning outcomes, as well as satisfaction. The study contributes to the pedagogical research by adapting and evaluating traditional peer learning concepts onto eLearning content creation. To practitioners, it reveals ways of creating high quality eLearning materials in spite of limited resources.
\end{abstract}

Keywords: eLearning, Blended Learning, peer learning, peer creation, peer assessment, Web Based Training

\footnotetext{
${ }^{1}$ Parts of this research were funded by the German Federal Ministry of Education and Research in the project BlendedContENT (www.blendedcontent.de), FKZ 01PF08022A
} 
German Universities are facing the challenge of increasing numbers of students and stagnating resources. Instructors are often forced to deliver their learning and teaching services through large scale lectures which suffer from a lack of interactivity and individualization. Different learning styles as well as previous experiences of students cannot be taken into account individually. eLearning was supposed to close this gap, at least partially through offering visually appealing, interactive learning materials making use of the multimedia possibilities of modern PCs. However, the production of high quality eLearning materials requires skills in education, content creation and maybe even programming or media editing. Many instructors do not have the resources to create these kinds of learning materials. Thus, university eLearning often still refers to electronic scripts and blackboards.

One way to face this challenge is to delegate more responsibility to learners, e.g., through peer creation. This term refers to learners creating content for their companions. Usually peer creation takes place in Web 2.0 media such as forums and Wikis, and is focussed on discussions between learners, often moderated by the instructor. We propose a different concept of eLearning peer creation. In this concept, students create multimedia and interactive learning materials for peers that are supposed to supplement or even replace traditional scripts in the long run. The concept is based on well-known approaches of peer learning, and is highly scalable. That way we try to create a constant flow of high quality learning materials to support our Information Systems (IS) courses.

The eLearning peer creation concept is applied onto two different processes of content creation, with students creating complex Web Based Trainings (WBTs) as well as more light-weighted multiplechoice tests. These processes were implemented in the IS courses of a German university. The peer created eLearning materials were then used in a large scale lecture, and evaluated with regard to learners' satisfaction, usage of the materials and learning outcomes. Results implicate that the peer created eLearning materials were well received and contributed to the learning experience.

Our research framework was based on Action Research (Susman and Evered, 1978): We diagnosed the problem situation as stated above, planned our actions based on existing peer learning concepts (section 2), took action by applying these concepts onto our eLearning peer creation processes (section 3 ), evaluated the results (sections 4 and 5) and specified our learning (sections 6 and 7).

This work contributes to the didactical research by applying traditional concepts of peer learning to multimedia eLearning material creation. It presents two different structured processes of content creation and proves their potential. To practitioners, this paper shows concrete ways of how to create high quality eLearning content with limited resources in mind.

\section{Basics of peer learning, multimedia learning and peer creation}

\subsection{Didactical basics of peer learning}

Learning is a change in the state of the human and its behaviour, and is based on experiences (Gagne, 1984). These experiences can occur in different situations, e.g., social interactions such as conversations and discussions (Alavi et al., 2002). The learning paradigm of Social Constructivism (Vygotsky, 1988) even posits that learning in general is an active process of constructing mental models through interaction with other human beings.

Peer learning is based on theories of Social Constructivism and refers to learning with and from companions of an equal status (Topping, 2005). There are different approaches towards peer learning involving different levels of equality between the learners. On the one hand, it can be based on strict role concepts with one peer acting similar to a traditional instructor (Topping, 2005, Damon, 1984), 
e.g. in peer tutoring. On the other hand, peer learning may be based on equal status and mutual engagement like in cooperative learning (Topping, 2005). Peer learning in general is supposed to have several positive effects on learners. Through discussions cognitive conflict arises fostering critical thinking and reflection (Damon, 1984) as well as improving communication skills (Topping, 2005). Learners gain responsibility for themselves and others (Mynard and Almarzouqi, 2006) and may gain more self-esteem. Team mates have also proven to increase the learners' motivation (Gerald, 2010).

Peer learning also promises to be a cost-effective way of learning and teaching. As early as 1987 Levin et al. revealed that peer learning outperformed other learning methods, including computerassisted instruction, in an elementary school setting (Levin et al., 1987). The cost-effectiveness of peer learning is also stated by Goto and Schneider (2010). However, since technological possibilities have increased, today peer learning is often supported by IT tools, e.g. in Virtual Communities. Since many Web 2.0 tools such as Blogs allow for ratings and comments, they are perfectly suited for peer assessment purposes (Chang et al., 2008). The mutual content creation in Web 2.0 contexts adds another element to peer learning: the concept of peer creation.

\subsection{Peer creation in educational contexts}

The concept of peer production or peer creation, the term used throughout this work, is rooted in the phenomenon of Co-creation which has gained importance in recent years (Zwass, 2010). Co-creation describes that the separation between producers and consumers is blurring in the digital age. Instead customers create value themselves, e.g. by adding articles to an online encyclopedia like Wikipedia. The resulting product is often referred to as user-generated content (UGC) which contains three defining aspects (OECD, 2007): It is published in some way on a platform in the Internet, its creation demands a certain amount of creative effort and it is created outside of professional routines. The last aspect also means that creation often is not commercially but intrinsically. A typical example of peer creation is Open-source software development, in which enjoyment of the development process is one of the main motivators for contributors (Lakhani and Wolf, 2003). One of the main advantages of peer creation is that often a mass of people is involved. Through the collaboration between these participants, including editing and validation, the final product is much more elaborated than that of single person (Blohm et al., 2011). The joint creation process is usually enabled through Social Media.

Since creating high quality learning materials is a resource intensive process, ideas of peer creation have been applied to educational contexts as well. In this case, learners as customers of a learning service add value to this service themselves by supplementing it with their own contents. The structure and goals of this process may be open or predetermined by an instructor (Auvinen, 2009). The focus however usually lies on the creation process itself and not on the resulting content. This peer created content is usually situational, it consists of single postings, discussions and edits. While those involved may highly benefit from the processes surrounding the content creation, the results are not designed as modular, re-usable and independent learning units. In addition, quality management of these contents arises as a major issue. Thus, our research focuses on peer creation of re-usable, modular eLearning materials. To address the challenge of quality management we adapt principles from peer learning theories as described above to the peer creation process.

\subsection{Principles for designing eLearning materials}

eLearning materials in general offer some advantages compared to traditional textbooks. One of the key advantages of multimedia learning is that the same contents can be explained in different ways, e.g., by narration and visualization, which means that different sensory memories are being addressed (Mayer, 2003). In addition, multimedia materials can offer different ways of interaction. Research in multimedia learning has identified several key principles for effective presentation of educational content (Moreno and Mayer, 2007, Clark and Mayer, 2008). These principles are used to avoid cognitive overload and express facts in an effective way. They include to use words and relevant 
visuals rather than words alone (multimedia), to exclude extraneous words and visuals (coherence), to use easy to understand language and address the learner directly (personalization), to point out key concepts which the WBT refers to at the beginning (pretraining), to divide the WBT into several sequences addressing different learning goals (segmenting) and to offer explanatory feedback for all assessments (feedback).

Apart from questions of presentation, eLearning materials like other forms of learning content should be developed following some instructional design principles. A set of well known principles comes from the ARCS model of instructional design (Keller, 1987). This model states that to raise motivation in learning, instructors should try to get students' attention (A), show the relevance of the learning goals (R), raise students' confidence to achieve these goals (C) and finally leave them satisfied with the results of their learning process $(\mathrm{S})$. To conclude, effective eLearning materials need to take into account cognitive aspects of presentation as well as instructional design aspects.

\section{Developing structured processes for eLearning peer creation}

\subsection{Background of the research project}

The study was based on two IS courses at a German university. The evaluation took place in the large scale lecture "Introduction to Business Informatics." Topics covered different basics of Information Systems, as well as data and business process modelling. The course is offered each semester to around 200-300 students. All students participating had the opportunity to borrow a mobile device, such as a netbook, in order to make full use of any eLearning materials. The course itself consisted of 13 lectures and four tutorial sessions of three hours each that focussed on applying modelling techniques. All learning materials and information were offered through the university's learning management system (LMS). Usage of all eLearning materials was generally optional since there was also a traditional script. Usage of the peer-created contents was not rewarded with any bonus points for the exam. Students attending the lecture however were asked by the instructor to participate in the peer creation activity that will be discussed later on.

\subsection{Adapting principles of peer learning to peer creation}

In this study we attempted to implement structured processes of eLearning peer creation and evaluate their benefit. As a first step we identified key principles of peer learning from the literature and adapted them to learning material peer creation (Table 1). These principles are based on requirements that have proven to be important for successful peer learning. We then implemented and evaluated two distinct creation processes. The first one transferred the concept of peer tutoring to content creation. Students would act as teachers and develop their own WBTs through the course of a whole semester. The WBTs were developed in a separate seminar but used in the already mentioned large scale lecture. The second peer creation process focussed on a fast, light-weighted peer-assessment activity where each student acted as both teacher and learner (or assessor and assessed).

\begin{tabular}{|l|l|}
\hline No. & Principle \\
\hline 1 & Clear and focused instructions to all participants (Hall and Stegila, 2003) \\
\hline 2 & Making learners responsible of their learning product, i.e. the WBT (Hall and Stegila, 2003) \\
\hline 3 & Ensuring sufficient expert knowledge of the creators (Damon, 1984) \\
\hline 4 & Training in didactics, communication/explanation skills and media usage (Damon, 1984, Webb, 2010) \\
\hline 5 & Regular supervision by the professional instructor (Damon, 1984, Hall and Stegila, 2003) \\
\hline 6 & $\begin{array}{l}\text { Offering well structured peer interactions (Webb, 2010) and peer assessments aiming at open-ended, } \\
\text { suggestive feedback (Topping, 1998) }\end{array}$ \\
\hline
\end{tabular}

Table 1. Principles that served as guideline for the creation process. 


\subsubsection{Process 1: Peer creation of Web Based Trainings}

Basically, the WBTs were created by students in a seminar on "Web Engineering". These are business and economics students that have already completed the "Introduction to Business Informatics" course. Most do not have any didactical, media editing or programming skills. Normally, students in this seminar would learn basics of Web Engineering from an example such as a homepage. For this purpose, in several seminar sessions they are introduced to the authoring software Adobe Flash. For the research project the seminar was supplemented by an additional instructor who focussed on didactical and factual aspects of the WBTs. Thus, while one instructor would teach the students basics of Web Programming like before, the second would offer feedback to contents and structure of the WBTs. Ideally this instructor should also be (and in this case was) the one who would eventually use the WBTs in his course, i.e. "Introduction to Business Informatics". The WBT creation process itself is very focussed on self-regulated learning and around the product of the WBT, which, in fact, makes up most of the final grade. The process is structured in several steps (Table 2).

\begin{tabular}{|l|l|}
\hline Step & Description \\
\hline 1 & $\begin{array}{l}\text { The instructors explain the course structure, expectations and grading modalities (principle 1) with } \\
\text { students being fully responsible of their WBT (principle 2). Students are informed in which course the } \\
\text { instructors might use their WBTs but that they retain full copyright of their work. }\end{array}$ \\
\hline 2 & $\begin{array}{l}\text { Each student is randomly assigned one topic from the course "Introduction to Business Informatics" } \\
\text { which they already participated in (principle 3). }\end{array}$ \\
\hline 3 & $\begin{array}{l}\text { They receive a summary of their topic explaining main contents that should be addressed and possible } \\
\text { learning goals (principle 1). Based on this, they search for further literature (principle 3). }\end{array}$ \\
\hline 4 & $\begin{array}{l}\text { Simultaneously students are introduced to basics of Web Design and structuring and visualizing } \\
\text { contents. They receive guidelines containing best-practices for WBT creation (principle 4). }\end{array}$ \\
\hline 5 & $\begin{array}{l}\text { They create a draft storyboard which is a table of contents explaining the learning goals of their WBT. } \\
\text { They receive timely feedback on this draft from the instructor (principle 5). }\end{array}$ \\
\hline 6 & $\begin{array}{l}\text { They create a final storyboard with all contents and assessments of the WBT. They again receive } \\
\text { individual feedback, this time in a session with one of the instructors (principle 5). }\end{array}$ \\
\hline 7 & $\begin{array}{l}\text { They create a first working version of the WBT which is peer-reviewed by two others students. To do } \\
\text { so, students receive guidelines on how to give qualitative, open-ended, suggestive advice (principle 6). }\end{array}$ \\
\hline 8 & $\begin{array}{l}\text { The students create the final WBT which, in this course, makes for most of the final grade (principle } \\
\text { 1). The best WBTs are chosen to be used in the course "Introduction to Business Informatics." }\end{array}$ \\
\hline
\end{tabular}

\section{Table 2. $\quad$ Process of WBT peer creation}

Students are first introduced to the seminar, especially its purpose, how the WBTs will be used, and how the creation process will work (step 1). They randomly receive one topic from the "Introduction to Business Informatics" course (step 2). Most of them have attended this course in an earlier semester and thus already have some knowledge concerning their topic. They also receive a short summary created by the instructors containing possible learning goals and contents for the WBT (step 3). Based on this, they look for further literature. After they have learned more about their topic they select and adjust about three to four of the learning goals from the summary for their WBTs. They write down these learning goals and a short description of each of those in a draft storyboard which reveals the proposed structure of the WBT. The instructors offer feedback regarding the storyboards to each student. Detailed work on the actual WBTs only starts after instructors and students have agreed upon a reasonable WBT structure and suitable learning goals (step 5). Based on this agreement the students create a final version of the storyboard containing all learning goals, texts, pictures and assessments (step 6). They receive a further feedback from the instructors on this final version. During the whole process of storyboard creation students already learn basics of Web Design (step 4). Based on what they have learned and their storyboards they finally create the WBT. A first version gets peerreviewed by two other students as a further measure of quality management (step 6). Then they create 
the final version which is assessed by the instructors (step 8). The best WBTs are used in the course "Introduction to Business Informatics".

During the whole process students may always contact the instructors for any questions. In addition they can orient themselves at different guidelines they receive. These contain templates for the WBT layout to ensure visual consistency of the WBTs as well as examples and hints to create animations, interactive elements and assessments. Students are advised to take the elements of the ARCS instructional design model into account as explained in section 2. Following the ARCS model, they should catch the users' attention by implementing different forms of interaction like controllable animations or various assessments. The relevance of the topic should be expressed by using examples from practice fields showing which problems are addressed by the learning contents. They should raise confidence by explaining what the learner will be able to do after completing the WBT, stated as learning goals right at the beginning. Finally, users should feel satisfied by completing the WBT in the way that every learning goal gets assessed at the end, so the user realizes what he has achieved so far. The examples also show how the principles of multimedia learning as explained in section 2 may be applied to the WBTs. E.g. students are taught that every learning goal should make up one encapsulated segment in the WBT (segmenting principle) or that complex issues should be explained by using words and additional visualizations (multimedia principle). Assessments should address all learning goals and should be enhanced by feedback explaining why an answer is right or wrong (feedback principle). These guidelines are supposed to enhance the quality of the WBTs and guarantee a similar look and feel (see Figure 1 for an impression).

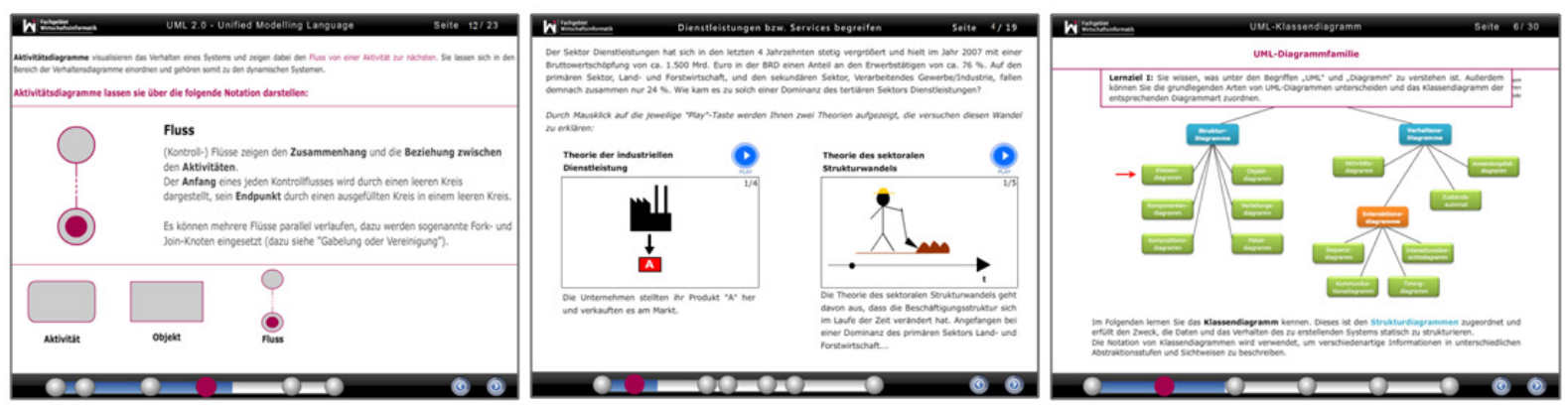

Figure 1. Examples of peer created WBTs.

Since the seminar is offered each semester with participant numbers ranging from about 15 to 40 , a continual production process of new materials is guaranteed. In this way, older WBTs can be replaced by new ones from time to time. In the evaluation semester, a total of 18 WBTs were used.

One thing to mention at this point is potential ethical issues. In contrast to voluntary forms of peer creation, the WBTs were a substitute for a regular exam. The peer creation process was extrinsically motivated through the course grade. This might raise concerns regarding the integration of the students into the creation process. To address this issue, students were informed at the beginning of the course that the WBTs they created might be used in the course "Introduction to Business Informatics". Participation in the seminar required them to grant the instructors the right to use the materials for teaching purposes. Still all students retained the full copyrights of their creations. Apart from that, no student had to attend the seminar but had at least one alternative course to choose. Additionally, regular evaluations of the seminar revealed that the students creating the WBTs perceived this procedure as interesting and satisfying (Wegener et al., 2010).

\subsubsection{Process 2: Peer creation of multiple-choice tests}

While the WBT creation was delegated to students from a Web Engineering seminar, the creation of multiple-choice tests was directly implemented into the large scale lecture "Introduction to Business Informatics" itself. As stated earlier, all students in the course had some sort of mobile device which allowed for IT-supported material creation. The activity we implemented was called "Co-Create Your 
Exam!" The idea behind this method is that in traditional frontal lectures, students' concentration will drop after some time. To avoid this decline of concentration, Olmsted (1999) recommends an active mid-lecture break, which gives students time to refresh, to reflect and to engage with one other.

During our activity, students create small true-or-false statements with regard to the topic they have just learned about (principle 3). Each student enters exactly three statements containing at least one true and one false item (principle 1). The statements are entered on their mobile device and sent to a database. Students then directly receive three items from their peers which they are supposed to solve. The usage of IT also allows for some supplementation of the traditional peer assessment process: Five items are randomly delivered to the instructor who solves them on-screen during the lecture, enabling a sort of interaction between students and instructor. Knowing that one's item might be shown onscreen is also supposed to enhance the items' quality (principle 5). In addition, all items are stored in a database and made available through the LMS. Quality management is implemented to the degree that any student solving one of the items is also supposed to contribute a five-star-rating (principle 6). After one week, just before the next lecture starts, the instructor chooses 20 of the best rated items which will be available on the LMS permanently as tests. In this way, the bridge between face-to-face sessions and online activities is closed, at least to some extent, since the items created during the lecture are carried over to the virtual space of the LMS. In addition, some of the items are used in the final exam (the multiple-choice part makes up about $30 \%$ of the exam), and thus the activity's name: "Co-Create Your Exam!" While the peer ratings help to find those items of a higher quality, the instructor is still responsible of choosing items that align with the actual learning goals of the course. Additionally, the students are told that the peer created items do not necessarily reflect the final exam with regard to difficulty and the priority of single topics.

The implementation of this process was subject to one major shortcoming: The final version of the application we used was only available from the seventh to the thirteenth lecture. While the activity of creating items and solving those of a peer was conducted from the beginning, transferring the data to a database and as a multiple-choice test to the LMS was only available about half way through the semester. This means that the peer-created multiple-choice test covered only about half of the topics.

\section{$4 \quad$ Evaluation design and instruments}

\subsection{Measurement of satisfaction}

Satisfaction with the course in general, as well as satisfaction with specific elements such as the learning materials, was measured by an online questionnaire. It contained items with regard to traditional dimensions of learner satisfaction (Cohen, 1981), including skill level of the instructor, instructor's rapport (empathy and friendliness), course structure, course difficulty and level of interaction. We supplemented the questionnaire by dimensions taken from eLearning success models for evaluating perceived quality of the eLearning materials. The items we added covered technological quality (such as the look and feel), flexibility and usefulness in the learning process (Sun et al., 2008, Ozkan and Koseler, 2009). In addition, we asked for perceived usage of the different eLearning materials. All items were rated on a Likert scale ranging from 1 (full agreement) to 5 (no agreement). The questionnaire was available online for several days before the exam. Participation was voluntary.

\subsection{Measurement of eLearning usage}

In addition to the questionnaire we used server logs to measure the actual usage of the different eLearning materials by each of the students. This was only possible since all names used in the LMS were fictional. The log system tracked whenever a student followed the link to one of the learning materials. While the LMS did not log how much time some person spent on a specific material, the tracking still allowed for counting how often a student used a specific form of eLearning material. 


\subsection{Measurement of learning outcomes}

A suitable way to measure learning outcomes should take into consideration the kind of knowledge learners are supposed to acquire. In this research project, we focussed on the cognitive outcomes (such as basic knowledge of terms in the IS domain) and understanding concepts (such as business process modelling). As suggested by Kraiger et al. (1993), we used a power test to measure these outcomes. It was a multiple-choice-test containing 20 items that were mutually created by two instructors. The questions were designed to cover the course's learning goals equally. In order to measure knowledge gains, the test was conducted two times, as a pre- and post-test, at the start of the semester during the first tutorial sessions (without any feedback on correct or incorrect answers) and online a few days before the exam. Participation in the second test was voluntary, but most students took part as preparation for the exam. Knowledge gain was measured as the difference between post- and pre-test.

With the results of the post-test we also conducted a split-half test reliability analysis. The twenty items were divided into two groups by the odd-even method. The post-test was taken by 248 students. From these, we excluded tests being conducted within less than five minutes which marked the fifth percentile of the data, hinting at random selection of at least several items. This reduced the sample to 233 tests. Between the two halfs of the test a total correlation of 0.558 was revealed to be significant at the level of 0.01 . The reliability computed by the Spearman-Brown formula was 0.72 which can be considered moderate, and suggests that the test can be used for estimating learning outcomes.

\section{$5 \quad$ Results}

\subsection{Results with regard to students' satisfaction}

We first present main results of the questionnaire with regard to the overall satisfaction, as well as the satisfaction with the eLearning materials and the peer assessment activity (Table 3).

\begin{tabular}{|c|c|c|c|}
\hline Dimension & Item & Mean & Stand. Dev. \\
\hline \multirow{4}{*}{$\begin{array}{l}\text { Course } \\
\text { Overall }\end{array}$} & Satisfaction & 2.38 & 0.852 \\
\hline & Comparison to Other Courses & 2.41 & 0.827 \\
\hline & Innovativeness & 1.88 & 0.869 \\
\hline & Recommendation & 2.37 & 1.079 \\
\hline \multirow{5}{*}{$\begin{array}{l}\text { Course } \\
\text { Structure }\end{array}$} & Structure & 1.98 & 0.827 \\
\hline & Contents & 2.70 & 0.993 \\
\hline & Relevance & 2.50 & 1.027 \\
\hline & Materials & 1.98 & 0.874 \\
\hline & Transparency of Requirements & 2.43 & 1.009 \\
\hline \multirow[t]{2}{*}{ Interaction } & Interactivity & 2.13 & 0.942 \\
\hline & Participation & 2.65 & 1.181 \\
\hline \multirow[t]{3}{*}{ Videos } & Appearance & 2.34 & 1.111 \\
\hline & Good For Recapitulation & 1.84 & 0.976 \\
\hline & Usage & 2.22 & 1.310 \\
\hline \multirow[t]{4}{*}{ WBTs } & Appearance & 2.11 & 0.941 \\
\hline & Interactivity & 2.09 & 0.882 \\
\hline & Good For Recapitulation & 2.02 & 0.887 \\
\hline & Usage & 2.62 & 1.043 \\
\hline \multirow{3}{*}{$\begin{array}{l}\text { Co-Create } \\
\text { Your Exam! }\end{array}$} & Is Fun & 2.72 & 1.101 \\
\hline & Useful & 2.41 & 1.061 \\
\hline & Usage & 2.75 & 1.230 \\
\hline
\end{tabular}

Table 3. Mean results of the questionnaire $(1=$ best score, $3=$ neutral, $5=$ lowest score $)$ 
128 students participated in the questionnaire. The course was moderately well perceived with an overall satisfaction rating of 2.38 . The most striking facts are that the perceived interactivity and quality of the learning materials in general received very good ratings (2.13 and 1.98), especially keeping in mind that this was a large scale lecture that usually lacks interactivity. The statement that the WBTs are useful to recapitulate the lecture was rated with a mean of 2.02 indicating a high level of quality of this peer created material. Overall, the WBTs scored on a similar level as the Videos from the lecture. Visual appearance and interactivity of the WBTs were rated high as well (2.11 and 2.09), which indicates a high perceived quality level. The activity "Co-Create Your Exam!" was less appreciated but still rated positively with values ranging from around 2.4 to 2.7 . One major factor behind these ratings may be that participation in this activity was requested during the face-to-face lectures, while usage of the pure eLearning materials was completely voluntary. The relatively high standard deviations of perceived usage of Videos, WBTs and "Co-Create Your Exam" indicate that learners indeed differ much with regard to their personal learning preferences.

The next step of our evaluation was to search for correlations between perceived usage of the peer created eLearning materials and learners' satisfaction. A Kolmogorov-Smirnov test in SPSS revealed that the data were not normally distributed. Thus, we had to use a non-parametric two-sided test (Kendall-Tau-b) to check for correlations (Table 4). Perceived usefulness and usage of the WBTs significantly correlate with overall satisfaction and satisfaction with content. Perceived usefulness and usage of "Co-Create Your Exam!" also correlate significantly with overall satisfaction as well as perceived interaction. The effect sizes are on a medium level (Cohen, 1992). Students making active use of the WBTs and the co-creation activity perceived the course to be more interactive and generally more satisfying. In contrast to this, the perceived usage of the Videos did not correlate with satisfaction or interactivity on a statistically significant level. This indicates that the less typical eLearning materials, the WBTs and co-created assessments, as well as the activating aspect of "CoCreate- Your Exam!" may in fact have contributed to course satisfaction and interactivity.

\begin{tabular}{|l|l|l|l|l|l|l|l|l|l|l|}
\hline & Satisf. & Content & Interact. & Materials & $\begin{array}{l}\text { Videos } \\
\text { Useful }\end{array}$ & $\begin{array}{l}\text { Videos } \\
\text { Usage }\end{array}$ & $\begin{array}{l}\text { WBTs } \\
\text { Useful }\end{array}$ & $\begin{array}{l}\text { WBTs } \\
\text { Usage }\end{array}$ & $\begin{array}{l}\text { Co-Cr. } \\
\text { Useful }\end{array}$ & $\begin{array}{l}\text { Co-Cr. } \\
\text { Usage }\end{array}$ \\
\hline Satisfaction & 1.000 & $.557^{* *}$ & $.276^{* *}$ & $.416^{* *}$ & $.313^{* *}$ & .127 & $.370^{* *}$ & $.321^{* *}$ & $.297^{* *}$ & $.159^{*}$ \\
\hline Content & $.557^{* *}$ & 1.000 & $.173^{*}$ & $.350^{* *}$ & $.278^{* *}$ & $.160^{*}$ & $.251^{* *}$ & $.237^{* *}$ & $.208^{* *}$ & .090 \\
\hline Interactivity & $.276^{* *}$ & $.173^{*}$ & 1.000 & $.405^{* *}$ & .092 & -.041 & $.278^{* *}$ & .083 & $.412^{* *}$ & $.242^{* *}$ \\
\hline Materials & $.416^{* *}$ & $.350^{* *}$ & $.405^{* *}$ & 1.000 & $.307^{* *}$ & .101 & $.406^{* *}$ & $.174^{*}$ & $.329^{* *}$ & $.151^{*}$ \\
\hline Vid. useful & $.313^{* *}$ & $.278^{* *}$ & .092 & $.307^{* *}$ & 1.000 & $.515^{* *}$ & $.324^{* *}$ & $.160^{*}$ & $.247^{* *}$ & .003 \\
\hline Vid. usage & .127 & $.160^{*}$ & -.041 & .101 & $.515^{* *}$ & 1.000 & .083 & .110 & -.036 & $-.244^{* *}$ \\
\hline WBT useful & $.370^{* *}$ & $.251^{* *}$ & $.278^{* *}$ & $.406^{* *}$ & $.324^{* *}$ & .083 & 1.000 & $.527^{* *}$ & $.346^{* *}$ & .075 \\
\hline WBT usage & $.321^{* *}$ & $.237^{* *}$ & .083 & $.174^{*}$ & $.160^{*}$ & .110 & $.527^{* *}$ & 1.000 & $.253^{* *}$ & $.203^{* *}$ \\
\hline CoCr useful & $.297^{* *}$ & $.208^{* *}$ & $.412^{* *}$ & $.329^{* *}$ & $.247^{* *}$ & -.036 & $.346^{* *}$ & $.253^{* *}$ & 1.000 & $.418^{* *}$ \\
\hline CoCr usage & $.159^{*}$ & .090 & $.242^{* *}$ & $.151^{*}$ & .003 & $-.244^{* *}$ & .075 & $.203^{* *}$ & $.418^{* *}$ & 1.000 \\
\hline
\end{tabular}

Table 4. Correlations between satisfaction and specific learning materials $\left(^{* *}\right.$ correlation significant with $p<.01,{ }^{*}$ correlation significant with $\left.p<.05\right)$

\subsection{Results with regard to students' learning outcomes}

First we compared the mean results of the pre- and post-power-tests. The mean score from the pre-test $(n=206)$ was 4.58 out of 20 , the mean score from the post-test $(n=233)$ was 8.85. A Mann-WhitneyU-Test revealed that the difference of the mean scores was significant at $p<.001$ and thus a general knowledge gain can be assumed. Since a Kolmogorov-Smirnov test showed that the results of the exam as well as the values of the media usage were not normally distributed, we again used KendallTau-b for the correlation analysis between media usage and learning success. In total, 164 students completed both tests and were incorporated in the analysis (Table 5). 
The first line in the table contains the correlations between usage of the eLearning materials and actual learning performance. The Videos show a significant correlation of .151. WBTs usage is also significantly correlated to learning outcomes. However, the correlation is not as strong as the one for the Videos. The usage of the online assessment created in the "Co-Create Your Exam!" activity does not correlate with the learning outcomes on a statistically significant level. However, a value of .057 means that the results nearly reached significance, probably due to the fact that these tests only covered about half of the course. With regard to its practical implications the correlations can only be considered of small effect size with values slightly above .1 (Cohen, 1992).

\begin{tabular}{|ll|l|l|l|l|}
\hline & & $\begin{array}{l}\text { Difference } \\
\text { Post-/Pre-Test }\end{array}$ & $\begin{array}{l}\text { Actual Usage } \\
\text { of Videos }\end{array}$ & $\begin{array}{l}\text { Actual usage } \\
\text { of WBTs }\end{array}$ & $\begin{array}{l}\text { Actual usage } \\
\text { of Co-Cr. } \\
\text { Assess. }\end{array}$ \\
\hline $\begin{array}{l}\text { Difference Post- } \\
\text { /Pre-Test }\end{array}$ & $\begin{array}{l}\text { Corr. Coeff. } \\
\text { Sig. (2-sided) }\end{array}$ & 1.000 & $.151^{* *}$ & $.109^{*}$ & .109 \\
.006 & 1.000 & .048 & .057 \\
\hline $\begin{array}{llll}\text { Actual Usage of } \\
\text { Videos }\end{array}$ & Corr. Coeff. & $.151^{* *}$ &. & .000 & $.328^{* *}$ \\
\hline $\begin{array}{llll}\text { Actual usage of } \\
\text { WBTs }\end{array}$ & Corr. Coeff. & $.109^{*}$ & $.368^{* *}$ & 1.000 & .000 \\
\hline $\begin{array}{l}\text { Actual Usage of Co- } \\
\text { Create Assessment }\end{array}$ & Corr. Coeff. & .109 & .000 &. & $.320^{* *}$ \\
\hline
\end{tabular}

Table 5. Correlations between eLearning usage and learning performance (** correlation significant with $p<.01, *$ correlation significant with $p<.05$ )

\section{$6 \quad$ Discussion of the results}

The mean results of the questionnaire revealed that the peer created WBTs were well accepted and highly appreciated by students. Perceived usefulness, as well as interactivity and appearance, received high ratings, suggesting a huge potential of the peer created WBTs. These results are supported by the correlation analyses. Perceived usefulness and usage of the WBTs both strongly correlated with overall course satisfaction. The actual usage also correlated on a significant level with the learning performance, although this correlation was quite small and can hopefully be improved during the next semesters.

It may be even more surprising though that the activity "Co-Create Your Exam" and the multiplechoice test resulting from this activity also contributed to the learning experience. While the activity scored lower than the WBTs and Videos with regard to satisfaction, it was still positively rated. Perceived usefulness and usage correlated significantly with perceived interaction and general satisfaction. In addition, the usage of the co-created multiple-choice test also correlated with learning performance but slightly missed statistical significance. One has to keep in mind, however, that the test was only available for about half of the lectures, a fact that may have flawed the data to some degree. Still, the results are promising, especially keeping in mind that the integration of this activity was nearly neutral with regard to the instructor's resources. The results indicate that even a light weighted eLearning peer creation activity may contribute to learning satisfaction and success.

However, while both peer created eLearning materials proved to be valuable supplementary materials, all interpretations of the correlations need to be taken with consideration. These correlations are not necessarily the result of a direct causal relationship. It is possible to assume that students being more engaged in the WBTs as well as the "Co-Create Your Exam!" activity and test were more motivated than their companions and would have scored higher anyway. However, since students in the questionnaire stated that the materials were helpful in their learning process, we still assume that the peer created eLearning materials contributed to both satisfaction as well as learning performance. 


\section{$7 \quad$ Summarization, limitations and conclusion}

This paper introduced two processes of peer creation. In the first process, students of a Web Engineering seminar created WBTs for their peers in a large scale lecture. In the second process, students created small multiple-choice items during each lecture which were made available as tests on the LMS. We evaluated these processes through satisfaction questionnaires, logs of the media usage and investigation of learning performance. The peer created eLearning materials were well received by students. Perceived usage of these materials significantly correlated with perceived interaction and overall satisfaction. Actual usage also correlated with learning outcomes. Thus, we were satisfied with the results of our first implementation. However, so far we have only adapted this process in IS courses. Results might differ with other target groups, especially those not confident with IT. These students might need other tools to create learning contents. Also, not all contents and learning goals might be suitable for being supplemented by WBTs or other peer creation processes. With regard to the missing rigorous experimental conditions, we cannot be certain of direct causal relations between usage of the material and satisfaction or performance. However, since the materials were generally perceived very well we can assume that correlations at least partially resulted from causal relations.

With regard to the resources necessary for implementation our results are similar to others stating that peer learning is time consuming in the beginning but cost-effective in the long term (Damon, 1984, Topping, 1996). While creating guidelines and IT-tools was indeed expensive, the supervision of the peer creation is less expensive for the instructors than creating all materials on their own.

Considering peer creation research and applications, our approach is less focussed on collaboration and the "wisdom of the crowds" phenomenon. Instead we implemented relatively strict structures, and relied on the interventions of an expert as measures of quality management, especially concerning the WBT creation process. Future research should investigate to what extend these expert interventions can be substituted by more peer interactions.

The WBT creation process we implemented is continually improved. We create new assignments, rework our guidelines and also try to improve our layout templates. Additionally, from time to time there are still flaws found and corrected. For this reason, we will have to further improve on the quality management process. It might make sense to reward students that find flaws in the WBTs and thus integrate the student community even more into the quality management process. We are also planning to have students create WBTs for more courses, maybe even outside the IS courses, to prove that the concept works in different domains.

\section{References}

Alavi, M., Marakas, G. and Yoo, Y. (2002). A Comparative Study of Distributed Learning Environments on Learning Outcomes. Information Systems Research, 13 (4), 404-415.

Auvinen, A. M. (2009). The challenge of quality in peer-produced eLearning content. eLearning Papers. Available: http://www.elearningeuropa.info/files/media/media21212.pdf

Blohm, I., Bretschneider, U., Leimeister, J. M. and Krcmar, H. (2011). Does collaboration among participants lead to better ideas in IT-based idea competitions? An empirical investigation. International Journal of Networking and Virtual Organisations, 9 (2), 106-122.

Chang, Y. J., Chang, Y. S. and Chen, C. H. (2008). Assessing Peer Support and Usability of Blogging Technology. Third 2008 International Conference on Convergence and Hybrid Information Technology, 1, 184-189.

Clark, R. C. and Mayer, R. E. (2008). Learning by viewing versus learning by doing: Evidence-based guidelines for principled learning environments. Performance Improvement, 47 (9), 5-13.

Cohen, J. (1992). A power primer. Psychological bulletin, 112 (1), 155-159.

Cohen, P. A. (1981). Student ratings of instruction and student achievement: A meta-analysis of multisection validity studies. Review of Educational Research, 51 (3), 281-309. 
Damon, W. (1984). Peer education: The untapped potential. Journal of Applied Developmental Psychology, 5 (4), 331-343.

Gagne, R. M. (1984). Learning outcomes and their effects: Useful categories of human performance. American Psychologist, 39 (4), 377-385.

Gerald, E. (2010). Peer effects, motivation, and learning. Economics of Education Review, 29 (3), 364-374.

Goto, K. and Schneider, J. (2010). Learning through Teaching: Challenges and Opportunities in Facilitating Student Learning in Food Science and Nutrition by Using the Interteaching Approach. Journal of Food Science Education, 9 (1), 31-35.

Hall, T. and Stegila, A. (2003). Peer mediated instruction and intervention. Wakefield: National Center on Accessing the General Curriculum. Available: http://aim.cast.org/learn/historyarchive/backgroundpapers/peer-mediated_instruction

Keller, J. (1987). Development and use of the ARCS model of instructional design. Journal of Instructional Development, 10 (3), 2-10.

Kraiger, K., Ford, J. K. and Salas, E. (1993). Application of cognitive, skill-based, and affective theories of learning outcomes to new methods of training evaluation. Journal of Applied Psychology, 311-328.

Lakhani, K. and Wolf, R. (2003). Why hackers do what they do: Understanding motivation and effort in free/open source software projects.

Levin, H. M., Glass, G. V. and Meister, G. R. (1987). Cost-effectiveness of computer-assisted instruction. Evaluation Review, 11 (1), 50-72.

Mayer, R. E. (2003). The promise of multimedia learning: using the same instructional design methods across different media. Learning and Instruction, 13 (2), 125-139.

Moreno, R. and Mayer, R. (2007). Interactive Multimodal Learning Environments. Educational Psychology Review, 19 (3), 309-326.

Mynard, J. and Almarzouqi, I. (2006). Investigating Peer Tutoring. ELT Journal, 60 (1), 13-22.

OECD (2007). Participative Web: User-Created Content. OECD. Available: http://www.oecd.org/dataoecd/57/14/38393115.pdf

Olmsted III, J. (1999). The mid-lecture break: When less is more. Journal of Chemical Education, 76 (4), 525-527.

Ozkan, S. and Koseler, R. (2009). Multi-dimensional students' evaluation of e-learning systems in the higher education context: An empirical investigation. Computers \& Education, 53 (4), 1285 1296.

Sun, P.-C., Tsai, R. J., Finger, G., Chen, Y.-Y. and Yeh, D. (2008). What drives a successful eLearning? An empirical investigation of the critical factors influencing learner satisfaction. Computers \& Education, 50 (4), 1183-1202.

Susman, G. I. and Evered, R. D. (1978). An assessment of the scientific merits of action research. Administrative science quarterly, 23 (4), 582-603.

Topping, K. (1998). Peer assessment between students in colleges and universities. Review of Educational Research, 68 (3), 249-276.

Topping, K. J. (1996). The effectiveness of peer tutoring in further and higher education: A typology and review of the literature. Higher Education, 32 (3), 321-345.

Topping, K. J. (2005). Trends in peer learning. Educational Psychology, 25 (6), 631-645.

Vygotsky, L. (1988). The genesis of higher mental functions. Cognitive development to adolescence: A reader, $61-79$.

Webb, N. M. (2010). Peer Learning in the Classroom. In International Encyclopedia of Education (Penelope, P., Eva, B. and Barry, M. Eds.), 636-642, Oxford, Elsevier.

Wegener, R., Menschner, P. and Leimeister, J. M. (2010). Analyse und Optimierung von Lehrdienstleistungen mittels Service Blueprinting - Konzeption und erste empirische Befunde. In Multikonferenz Wirtschaftsinformatik (MKWI) 2010 Göttingen. 383-395.

Zwass, V. (2010). Co-Creation: Toward a Taxonomy and an Integrated Research Perspective. International Journal of Electronic Commerce, 15 (1), 11-48. 